\title{
A Multimethod Analysis of Impulsivity in Nonsuicidal Self-Injury
}

\author{
Catherine R. Glenn and E. David Klonsky \\ Stony Brook University
}

\begin{abstract}
Impulsivity has been proposed as an important construct in nonsuicidal self-injury (NSSI). Yet, research on the relationship of impulsivity to NSSI has been mixed. The present study clarified this relationship using a multifaceted measure of impulsivity (i.e., UPPS Impulsive Behavior Scale), and a computer-based behavioral measure of inhibitory control (i.e., a stop-signal task). Participants were 82 confirmed self-injurers and 86 controls recruited from a college population. Self-injurers and controls performed similarly on the stop-signal task. On the UPPS, self-injurers were best distinguished by Urgency (committing rash decisions when faced with negative emotions), and distinguished to a lesser degree by lack of Premeditation (inability to delay action in order to plan) and Sensation Seeking (seeking excitement and adventure). Among self-injurers, lack of Perseverance (inability to stay with a task through completion) predicted more recent and frequent NSSI. Conceptual and clinical implications are discussed.
\end{abstract}

Keywords: self-injurious behavior, deliberate self-harm, nonsuicidal self-injury, impulsive behavior, impulsivity

Nonsuicidal self-injury (NSSI) refers to the deliberate and direct injuring of body tissue without suicidal intent, and for purposes not socially sanctioned (Favazza \& Conterio, 1989; Nock \& Prinstein, 2004; Whitlock, Eckenrode, \& Silverman, 2006). At least 14 different methods of NSSI have been identified, though the most common forms are skin-cutting, burning, and scratching (Ross \& Heath, 2002; Whitlock et al., 2006). Although historically NSSI was thought to occur only in psychiatric populations, it has become clear that NSSI occurs in nonpsychiatric populations and has become a significant public health problem among adolescents and young adults. Approximately $8 \%$ of

Catherine R. Glenn and E. David Klonsky, Department of Psychology, Stony Brook University.

E. David Klonsky is now at the Department of Psychology, University of British Columbia.

This study was supported in part by NIH grant MH08009601 awarded to Dr. Klonsky, and the Office of the Vice President for Research at Stony Brook University. We thank Dr. Richard Ridderinkhof at the University of Amsterdam for supplying the stop-signal task and Dr. Greg Hajcak and Dan Foti at Stony Brook University for helping set up the task in the laboratory.

Correspondence concerning this article should be addressed to E. David Klonsky, UBC Department of Psychology, 2136 West Mall, Vancouver, B.C., V6T 1Z4, Canada. E-mail: edklonsky@gmail.com children ages 12 to 14 (Hilt, Nock, LloydRichardson, \& Prinstein, 2008), 14-15\% of adolescents (Laye-Gindhu, \& Schonert-Reichl, 2005; Ross \& Heath, 2002), and $17 \%$ or more of college students (Gratz, 2001; Whitlock et al., 2006) report having self-injured. Concern about NSSI is amplified because the behavior is associated with a range of negative mental health variables, including depression, anxiety, borderline personality disorder, and suicidality (Andover, Pepper, Ryabchenko, Orrico, \& Gibb, 2005; Hawton, Rodham, Evans, \& Weatherall, 2002; Klonsky, Oltmanns, \& Turkheimer, 2003).

NSSI's high rates and negative mental health implications have led two Diagnostic and Statistical Manual of Mental Disorders version 5 (DSM-V) Workgroups (i.e., Child and Adolescent Disorders and Mood Disorders) to consider classifying NSSI as a distinct syndrome in DSM-V. Currently, in DSM-IV, NSSI is mentioned only once, as a symptom of borderline personality disorder (BPD); however, for decades, many have suggested that NSSI represents a disorder of impulse control. Pattison and Kahan (1983) proposed a "Deliberate Self-Harm Syndrome" to be classified as an impulse control disorder based on the conceptualization that self-injurers have an inability to resist the impulse, or urge, to injure themselves. Favazza and Conterio (1989) further supported this classification with their study of 
240 female self-injurers who exhibited a lack of deliberation, or "impulsivity," in their selfinjurious behaviors. In support of this notion, recent research has found that many self-injurers spend less than 5 minutes contemplating a selfinjurious act (Nock \& Prinstein, 2005). In addition, there is evidence that individuals who engage in NSSI are more likely to engage in other impulsive behaviors, including binge eating, alcohol and/or drug abuse, sexual promiscuity, gambling, and others (Evans \& Lacey, 1992; Herpertz, Sass, \& Favazza, 1997; Zlotnick et al., 1996). The high co-occurrence of these impulsive behaviors has led some to consider NSSI as part of a "multiimpulsive personality disorder" (Lacey \& Evans, 1986; Evans \& Lacey, 1992). However, the reasoning behind this argument is problematic; specifically, this logic assumes that self-injurers want to resist the urge to engage in NSSI, which may not be accurate given the reinforcement provided by the behavior (e.g., emotion regulation).

Despite the many suggestions that selfinjurers are impulsive, research on impulsivity in NSSI has yielded mixed results. Evans, Platts, and Liebenau (1996) found that, in a sample of inpatients, self-injury "repeaters" were more impulsive than self-injury "firsttimers," who in turn were more impulsive than norms from the general population. However, other studies have found that self-injurers and controls only differ for particular aspects of impulsivity (e.g., future planning; Herpertz et al., 1997), that impulsivity correlates with the degree of NSSI among self-injurers but fails to distinguish injurers from controls (Simeon et al., 1992), and that impulsivity only distinguishes female, and not male, self-injurers from controls (Hawton et al., 2002).

One reason for these mixed findings may be the variety of ways impulsivity can be conceptualized and assessed. Impulsivity is a heterogeneous construct observed in many forms of psychopathology, including attention deficit hyperactivity disorder (ADHD), manic episodes in bipolar disorder, personality disorders, impulse control disorders, and others (Moeller, Barratt, Dougherty, Schmitz \& Swann, 2001). Across these various disorders, impulsivity has been used to describe different types of features from novelty seeking and risk-taking to nonplanning and a short attention span. In NSSI specifically, previous studies have examined impulsivity utilizing a variety of scales that assess different aspects of the construct, including the Eysenck IVE (Eysenck \& Eysenck, 1991), the Barratt Impulsiveness Scale (BIS; Barratt, 1985), the Sensation Seeking Scale (SSS; Zuckerman, 1994), and a subset of items from the Plutchik impulsivity scale (Plutchik et al., 1989).

In an attempt to organize the multiple definitions of impulsivity into a comprehensive measure, Whiteside and Lynam (2001) created the UPPS Impulsive Behavior Scale. The UPPS was created through a series of factor analyses that incorporated the Five Factor Model of personality (FFM; McCrae \& Costa, 1990) and eight impulsivity scales, including: the BIS, IVE, SSS, and others. Four superordinate domains associated with impulsive behavior were identified: (a) Urgency: the tendency to commit rash, regrettable actions in the face of negative affect, (b) Perseverance (lack of): the ability (or inability) to stay with a task through completion, (c) Premeditation (lack of): the ability (or inability) to delay action in order to deliberate and plan, and (d) Sensation Seeking: the tendency to seek excitement and adventure. Importantly, the structure, validity, and clinical utility of the UPPS model of impulsivity were subsequently confirmed by multiple investigators using both self-report and interview methodologies (d'Acremont \& van der Linden, 2007; Fischer, Smith, \& Anderson, 2003; Miller, Flory, Lynam, \& Leukfield, 2003; Smith et al., 2007; Whiteside \& Lynam, 2003; Whiteside, Lynam, Miller, \& Reynolds, 2005). The UPPS model has been used to clarify the nature of impulsivity in a variety of disorders, including: ADHD (Miller et al., 2003), alcohol abuse (Whiteside \& Lynam, 2003), borderline personality disorder (Whiteside et al., 2005), bulimia (Fischer et al., 2003), and depression (d'Acremont \& van der Linden, 2007).

The first goal of the current study is to examine impulsivity in NSSI utilizing the multidimensional UPPS measure. It is hypothesized that self-injurers will exhibit some forms of impulsivity but not others. Research on the functions of NSSI indicates that self-injurers have difficulty regulating intense negative emotions and use NSSI to cope with these emotions (Klonsky et al., 2003; Klonsky, 2007; Nock \& Prinstein, 2004). Based on this research, we hypothesize that self-injurers will exhibit higher Urgency (which examines the tendency to engage in rash behaviors in the face of negative 
emotions) than noninjurers. In addition, consistent with previous research that self-injurers exhibit poorer planning than noninjurers (Evans et al., 1996; Hawton et al., 2002; Herpertz et al., 1997), it is predicted that self-injurers will exhibit less Premeditation than noninjurers. However, it is anticipated that there will be no differences between self-injurers and noninjurers in Perseverance or Sensation Seeking because previous studies have failed to link these specific aspects of impulsivity to NSSI (Herpertz et al., 1997; Simeon et al., 1992).

However, the UPPS model is only one way to conceptualize impulsivity. Therefore, the second goal of the present study is to supplement the UPPS self-report assessment with a measure that assesses another facet of impulsivity: a laboratory-based, behavioral measure of inhibitory control (i.e., a stop-signal task). Behavioral measures are valuable because they do not have the same limitations as self-report instruments (e.g., subjective bias, memory bias). In addition, they are particularly important because previous research has found low convergence between self-report and behavioral measures of impulsivity (Gerbing, Ahadi, \& Patton, 1987; Enticott, Ogloff, \& Bradshaw, 2006). The stop-signal task (SST; Logan \& Cowan, 1984; Logan, 1994) estimates one's ability to quickly and successfully inhibit a behavioral response, and thus can be utilized as an index of inhibitory control. Insofar as NSSI has been conceptualized as an inability to inhibit self-injurious behaviors (Favazza \& Conterio, 1989; Pattison \& Kahan, 1983), individuals who engage in NSSI may be characterized by deficits in the inhibitory control of behavior. Indeed, Logan, Schachar, and Tannock (1997) found inhibitory control differences using a stop-signal task with individuals high and low on self-reported impulsivity. Stop-signal tasks have also been used to demonstrate inhibitory control differences between ADHD and control children (see review: Alderson, Rapport, \& Kofler, 2007).

\section{Method}

\section{Participants and Measures}

One thousand one hundred and ten college students from lower-level psychology classes were screened for a history of 12 NSSI behaviors, including skin-cutting, burning, and others (see
ISAS in Measures section for the full list of NSSI behaviors). Approximately 216 students (19.4\%) endorsed having engaged in at least one NSSI behavior, a rate consistent with previous research in college samples (Klonsky \& Olino, 2008; Whitlock et al., 2006). From this original self-injuring sample, 82 self-injurers were willing to participate in the study. The total sample included 168 students: 82 confirmed self-injuring participants and 86 confirmed noninjuring control participants; all participants completed the study in a single lab session.

\section{Diagnostic Variables}

Patient Health Questionnaire (PHQ; Spitzer, Kroenke, \& Williams, 1999). Axis-I symptoms were assessed with the PHQ. The PHQ is an 83-item self-report questionnaire that assesses the DSM-IV symptoms associated with four types of psychological problems: depression, anxiety, eating, and substance/alcohol disorder.

Inventory of Statements About Self-Injury (ISAS; Klonsky \& Glenn, 2009; Klonsky \& Olino, 2008). The ISAS measures the frequency and functions of NSSI. Recent research found the ISAS to be a reliable and valid measure of NSSI frequency and functions in a large sample of young adults (Klonsky \& Glenn, 2009; Klonsky $\&$ Olino, 2008). The first section of the ISAS assesses the lifetime frequency of 12 different NSSI behaviors performed "intentionally (i.e., on purpose) and without suicidal intent" (i.e., banging/hitting self, biting, burning, carving, cutting, interfering with wound healing, needlesticking, pinching, hair pulling, rubbing skin against rough surfaces, severe scratching, and swallowing chemicals) and was used to screen the sample for a history of NSSI.

Structured Interview for Non-Suicidal SelfInjury. A structured interview for NSSI was designed for this study to confirm a history of NSSI (i.e., the frequency of the NSSI methods assessed by the ISAS) and to assess other characteristics of NSSI (e.g., age of onset, date of most recent instance of NSSI).

\section{Impulsivity}

UPPS Impulsive Behavior Scale (UPPS; Whiteside \& Lynam, 2001). As previously described, the UPPS assesses four traits that lead 
to impulsive behavior: Urgency, (lack of) Perseverance, (lack of) Premeditation, and Sensation Seeking. The full UPPS scale is composed of 45 items that are rated on a 4-point scale from agree strongly to disagree strongly. This study utilized the UPPS 16-item short-form which consists of four items from each impulsivity subscale. The short-form was created by selecting the four items from each subscale that had the highest item-total correlations in the original study (Whiteside \& Lynam, 2001). Internal consistencies for the UPPS short-form were very good in the present study: alphas ranged between 0.79 and 0.85 for each of the four subscales. Intercorrelations among the subscales ranged from -.01 to .51 (median $=.16)$, suggesting that the subscales assess nonredundant aspects of impulsivity.

Stop-signal task (Logan \& Cowan, 1984; Logan, 1994). The stop-signal task (SST) is a behavioral measure of inhibitory control, which requires participants to make quick decisions about visual stimuli, and to withhold their response on some trials. In this task, participants complete a reaction time task where they are asked to categorize visual stimuli presented on a computer screen (e.g., pressing the left key whenever a left arrow appears on the screen). However, on approximately $25 \%$ of these trials, a stop-signal (e.g., a visual cue stimulus, such as the arrow turning blue) is presented following the onset of the imperative stimulus (e.g., the original white arrow). An algorithm (see Logan et al., 1997) is utilized to track the participant's performance and identify the threshold where the participant is able to successfully inhibit his or her responses $50 \%$ of the time (for a detailed description of the SST see Logan \& Cowan, 1984; Logan, 1994). The SST provides measures of reaction time, error rate (i.e., percentage of failed inhibits to stop-signals), stopsignal delay (i.e., amount of time elapsed between the onset of the imperative stimulus and the onset of the stop-signal), and the stopsignal reaction time (SSRT; i.e., the maximum amount of time that can elapse between the imperative stimulus and stop-signal, such that a behavioral response can still be inhibited). The SSRT is the main dependent measure used to assess behavioral inhibition. A faster (smaller) SSRT indicates a quick stop process and greater inhibitory control; conversely, a slower (larger)
SSRT demonstrates a slower stop process and less inhibitory control, or longer behavioral inhibition. The SSRT for each subject was calculated, as described in Logan et al. (1997).

\section{Procedure}

The procedure was the same for all participants except that only the self-injuring group participated in the full Structured Interview for NSSI. After the study procedure was explained and consent was obtained, demographic information, including gender, age, and ethnicity, was collected from all participants. First, NSSI history was confirmed for both groups with a brief interview (i.e., the first part of the Structured Interview for NSSI). Second, participants completed the stop-signal task. Next, all participants completed the self-report questionnaires: PHQ and UPPS. Finally, self-injuring participants completed the remaining questions in the Structured Interview for NSSI.

\section{Results}

\section{Demographic, Clinical, and NSSI Characteristics}

There were not significant gender differences between the self-injuring ( $73.2 \%$ female) and noninjuring groups (68.6\% female). However, noninjurers (mean age 19.8) were slightly older than the self-injurers (mean age 19.1) $[t(166)=$ $-2.47, p<.02$ ]. In addition, there were significantly more Asian students in the noninjuring group $\left[\chi^{2}(1,168)=11.45, p<.01\right]$, and more students of mixed ethnic backgrounds, who rated their ethnicity as "other," in the selfinjuring group $\left[\chi^{2}(1,168)=6.53, p<.02\right]$. In regard to the clinical variables, the self-injuring group had significantly more participants who endorsed full diagnostic criteria for major depression $(18.3 \%$ of the self-injurers compared to $5.8 \%$ of the controls) $\left[\chi^{2}(1,168)=6.23, p<\right.$ $.02]$, generalized anxiety disorder $(14.6 \%$ of the self-injurers compared to $1.2 \%$ of the controls) $\left[\chi^{2}(1,168)=10.67, p<.01\right]$, and alcohol abuse $(34.2 \%$ of the self-injurers compared to $14.0 \%$ of the controls) $\left[\chi^{2}(1,168)=9.44\right.$, $p<.01]$ as assessed by the PHQ.

The mean age of onset of NSSI was 13 years of age $(S D=2.9)$. Skin-cutting was the most common NSSI behavior (endorsed by $80.5 \%$ of 
the sample; $M d n=15.0, S D=185.7$, Range 1 to 1000$)$, followed by banging/hitting $(69.5 \%$; $M d n=10.0, S D=89.9$, Range 1 to 500$)$, severe scratching $(52.4 \% ; M d n=10.0, S D=$ 314.8 , Range 1 to 2000), and pulling hair $(42.7 \% ; M d n=20, S D=840.0$, Range 1 to 5000). Almost all (96\%) self-injurers engaged in more than one method of NSSI and most $(81 \%)$ had engaged in three or more NSSI methods in their lifetime. The majority of selfinjurers $(53.7 \%)$ had engaged in NSSI in the past 12 months.

\section{Impulsivity}

First, group differences in impulsivity were examined on the UPPS Impulsive Behavior Scale. Means and standard deviations for the impulsivity variables, as well as $p$ values and effect-sizes for group-comparisons, are presented in Table 1. Results indicate significant differences between the self-injurers and noninjurers on the UPPS Urgency, lack of Premeditation, and Sensation Seeking subscales, with the largest effect for Urgency. Significant group differences were not found for the lack of Perseverance scale. To examine whether these impulsivity scales relate to NSSI even when controlling for diagnostic differences, we conducted a series of one-way analyses of covariance (ANCOVAs). The relationship between Urgency and NSSI remained significant even when controlling for depression, $F(1,165)=6.82, p=.01$, anxiety, $F(1,165)=4.38, p=.04$, and alcohol abuse, $F(1,165)=10.3, p=.002$. The relationship between lack of Premeditation and NSSI also remained significant when controlling for depression, $F(1,165)=5.01, p=.03$, anxiety, $F(1$, $165)=4.99, p=.03$, and alcohol abuse, $F(1$, $165)=5.28, p=.02$. However, the relationship between Sensation Seeking and NSSI was reduced below the threshold for statistical significance when controlling for depression, $F(1$, $165)=3.34, p=.07$, anxiety, $F(1,165)=2.99$, $p=.09$, and alcohol abuse, $F(1,165)=3.47$, $p=.06$.

We also examined the UPPS scales in relation to recency and frequency of NSSI among those with histories of NSSI. To examine recency of NSSI, the self-injurers were divided into two groups: (a) "current" self-injurers $(n=$ 44), who had injured themselves within the past 12 months, and (b) past self-injurers ( $n=$ 38), who had not injured within the past 12 months. As presented in Table 2, a series of $t$ tests indicated that "current" self-injurers had higher scores on the UPPS lack of Perseverance subscale. No differences were found for Urgency, lack of Premeditation, or Sensation Seeking subscales. To examine NSSI frequency in relation to UPPS dimensions, we created a total NSSI frequency scale of all 12 NSSI behaviors (i.e., the summation of all NSSI acts; see ISAS description for the full list of behaviors). Spearman correlations were utilized because the distribution of NSSI frequency con-

Table 1

Impulsivity Scores for the Self-Injuring and Noninjuring Control Groups

\begin{tabular}{|c|c|c|c|c|c|c|}
\hline Variable & $\begin{array}{l}\text { Self-injurers } \\
\qquad M(S D)\end{array}$ & $\begin{array}{c}\text { Noninjurers } \\
M(S D)\end{array}$ & $t$ & $d f$ & $p$ & Cohen's $d$ \\
\hline \multicolumn{7}{|l|}{ UPPS } \\
\hline Total & $38.43(8.19)$ & $34.27(6.40)$ & 3.68 & 166 & $<.001$ & .57 \\
\hline Urgency & $11.05(3.08)$ & $9.45(2.98)$ & 3.41 & 166 & .001 & .53 \\
\hline (lack of) Perseverance & $7.46(2.83)$ & $7.20(2.45)$ & .65 & 166 & .52 & .10 \\
\hline (lack of) Premeditation & $8.39(2.88)$ & $7.31(2.52)$ & 2.58 & 166 & .01 & .40 \\
\hline Sensation seeking & $11.52(3.51)$ & $10.30(3.38)$ & 2.30 & 166 & .02 & .35 \\
\hline \multicolumn{7}{|l|}{ Stop-Signal Task } \\
\hline $\begin{array}{l}\text { Reaction time (at percent failed } \\
\text { inhibits) (msec) })^{\mathrm{a}}\end{array}$ & $362.02(35.22)$ & $371.19(40.52)$ & -1.49 & 150 & .14 & .24 \\
\hline Percent failed inhibits $(\%)$ & $52.15(4.61)$ & $51.34(4.03)$ & 1.14 & 150 & .26 & .19 \\
\hline Stop-signal delay (msec) & $150.98(45.69)$ & $154.86(42.13)$ & -.54 & 150 & .59 & .09 \\
\hline $\begin{array}{l}\text { Stop-signal reaction time } \\
\quad(\text { SSRT })(\mathrm{msec})\end{array}$ & $214.30(30.85)$ & $217.73(34.73)$ & -.64 & 150 & .52 & .10 \\
\hline
\end{tabular}

${ }^{\text {a }}$ Reaction time at percent failed inhibits is calculated with a tracking algorithm that aims to find the reaction time at which participants make $50 \%$ errors, therefore approximating the median reaction time for each subject. 
Table 2

Impulsivity Scores for the Current and Past Self-Injurers

\begin{tabular}{|c|c|c|c|c|c|c|}
\hline Variable & $\begin{array}{l}\text { Current self-injurers } \\
\qquad M(S D)\end{array}$ & $\begin{array}{c}\text { Past self-injurers } \\
M(S D)\end{array}$ & $t$ & $d f$ & $p$ & Cohen's $d$ \\
\hline \multicolumn{7}{|l|}{ UPPS } \\
\hline Total & $40.41(8.68)$ & $36.13(7.00)$ & -2.43 & 80 & .02 & .54 \\
\hline Urgency & $11.52(3.17)$ & $10.50(2.93)$ & -1.51 & 80 & .14 & .34 \\
\hline (lack of) Perseverance & $8.25(2.90)$ & $6.55(2.49)$ & -2.82 & 80 & .01 & .63 \\
\hline (lack of) Premeditation & $8.86(3.19)$ & $7.84(2.40)$ & -1.62 & 80 & .11 & .36 \\
\hline Sensation seeking & $11.77(3.49)$ & $11.24(3.57)$ & -0.69 & 80 & .14 & .15 \\
\hline \multicolumn{7}{|l|}{ Stop-Signal Task } \\
\hline $\begin{array}{l}\text { Reaction time (at percent failed } \\
\text { inhibits) (msec) })^{\mathrm{a}}\end{array}$ & $363.07(36.69)$ & $360.72(33.81)$ & -0.29 & 76 & .77 & .07 \\
\hline Percent failed inhibits $(\%)$ & $52.05(5.18)$ & $52.27(3.88)$ & 0.21 & 76 & .83 & .05 \\
\hline Stop-signal delay (msec) & $153.08(48.74)$ & $148.40(42.21)$ & -0.45 & 76 & .66 & .10 \\
\hline $\begin{array}{l}\text { Stop-signal reaction time } \\
\quad(\text { SSRT })(\mathrm{msec})\end{array}$ & $212.26(32.49)$ & $216.82(28.99)$ & 0.65 & 76 & .52 & .15 \\
\hline
\end{tabular}

${ }^{a}$ Reaction time at percent failed inhibits is calculated with a tracking algorithm that aims to find the reaction time at which participants make $50 \%$ errors, therefore approximating the median reaction time for each subject.

tained a large number of outliers. Results indicate a positive relationship between the frequency of NSSI and the lack of Perseverance $(\rho=.35, p=.001)$ and lack of Premeditation subscales $(\rho=.30, p<.01)$. In addition, this relationship remained robust after controlling for Axis I symptomatology, including depression, anxiety, and alcohol abuse ( $\rho s=.30$ and .31 , respectively).

Finally, differences between self-injurers and noninjurers in impulsivity were examined on the stop-signal task. Valid stop-signal data were available for 152 of the 168 participants. Table 1 displays the stop-signal task measures of performance (see description in Measures section) for both groups. As discussed above, the main dependent variable is the stop-signal reaction time (SSRT), which denotes the level of inhibitory control. Results indicate no difference in SSRT between the self-injuring and noninjuring groups $(p=.60)$. In addition, SSRT did not relate to NSSI frequency or recency (see Table 2). Moreover, correlations between the stop-signal task and the UPPS scales were small and nonsignificant for the overall sample and for the self-injuring and controls groups ( $r$ s ranged from -0.18 to 0.26 ).

\section{Discussion}

Findings from the current study were largely in line with expectations, with some notable exceptions. Self-injurers were best character- ized by problems with Urgency, which indicates a tendency to engage in rash behaviors in the face of negative affect. Elevated Urgency is consistent with previous research on emotion in NSSI. Numerous studies have shown selfinjurers to be more emotionally dysregulated than noninjurers (Gratz \& Roemer, 2008; Heath, Toste, Nedecheva, \& Charlebois, 2008). In addition, self-injurers report experiencing frequent intense negative emotions and using NSSI primarily as a means to cope with this negative emotional experience (Klonsky et al., 2003; Klonsky, 2007; Nock \& Prinstein, 2004). Taken with the current study's findings, one possible interpretation of greater Urgency in NSSI may be that self-injurers are (a) more emotionally dysregulated than noninjurers, (b) more likely to commit rash decisions in the face of these negative emotions, and (c) therefore use self-injury as a behavior to decrease these negative experiences.

Although to a lesser degree than Urgency, self-injurers were also distinguished by less Premeditation (i.e., the inability to delay action in order to deliberate or plan) and more Sensation Seeking (i.e., the tendency to seek excitement and adventure). Self-injurers' lack of Premeditation is consistent with previous research that has consistently documented poor planning in NSSI (Evans et al., 1996; Hawton et al., 2002; Herpertz et al., 1997). In addition, although self-injurers and controls differed on a number of clinical variables (i.e., depression, anxiety, 
and alcohol abuse), controlling for these variables did not eliminate the overall differences in Urgency or Premeditation. Differences in Sensation Seeking are surprising in light of previous research that did not find self-injurers to be distinguished by this trait (Simeon et al., 1992). However, the group differences in Sensation Seeking decreased substantially (and were no longer significant) after controlling for the three clinical variables, suggesting that the relationship of Sensation Seeking to NSSI may not be direct.

Low Perseverance (i.e., the ability to stay with a task to completion) did not distinguish self-injurers from noninjurers. However, among individuals with a history of NSSI, low Perseverance characterized those who had selfinjured more frequently and more recently. It is possible that, within the self-injuring group, high Perseverance distinguishes those who are better able to resist NSSI urges and to stop self-injuring. In contrast, low Perseverance might indicate diminished ability to carry out formal or informal interventions meant to stop self-injurious behaviors. In addition, NSSI frequency (but not recency) was related to less Premeditation. Less Premeditation indicates a reduced ability to foresee the consequences of maladaptive behaviors, and thus may indicate an increased likelihood of acting on a selfinjurious urge. It is therefore not surprising that this variable is associated with more frequent NSSI.

Despite differences on self-reported measures of impulsivity, self-injurers were not distinguished from noninjurers on behavioral measures derived from the stop-signal task. Additionally, stop-signal measures did not distinguish current injurers from past injurers. These null results are inconsistent with our hypothesis, which was based on previous research using the stop-signal task with other impulsive groups (e.g., Aldersen et al., 2007; Logan et al., 1997). These null results could be interpreted in a few ways. One possibility is that self-injurers have a normative capacity for inhibitory control. However, results from this study, specifically the high Urgency observed in self-injurers, suggest that negative affect often provides the context for impulsive behaviors. Therefore, another possible interpretation is that self-injurers may only exhibit differences in behavioral measures of impulsivity in the context of negative emotions. Whereas participants with ADHD may perform worse on the stop-signal task due to trait-related inhibitory control deficits, participants who engage in NSSI may only exhibit negative state-related inhibitory control deficits. Therefore, future studies might address this possibility by examining how mood manipulations impact performance on behavioral tests of impulsivity in NSSI.

To the extent that impulsivity causes or maintains NSSI, assessing impulsivity in clinical practice could be useful. For instance, selfinjurers who exhibit elevated Urgency may benefit from treatment focused on more adaptive emotion regulation or coping strategies to use when faced with negative affect. In addition, low Perseverance, which typified the more recent self-injurers, may be related to low selfcontrol and/or low distress tolerance (e.g., boredom and fatigue). Increasing an individual's ability to persist through unpleasant circumstances may be the key to helping self-injurers abstain from self-injury in the long-term. Given these treatment implications, it is clear how components of Dialectical Behavior Therapy (DBT; Linehan, 1993), particularly those modules that emphasize emotion regulation and distress tolerance, would be effective with selfinjurers.

The present study has several limitations. First, the sample consists of college students, who represent only a subset of self-injurers. Second, the range of impulsivity may be restricted in a college sample. Taken together, these shortcomings suggest the need to examine the NSSI-impulsivity relationship in treatmentseeking populations (e.g., Janis \& Nock, 2009). Third, the current study was not able to examine the relationship between impulsivity and measures of emotionality; future studies should examine the overlap and potential interaction between measures of negative affectivity and/or emotion regulation with impulsivity in the etiology and maintenance of NSSI. Lastly, due to the cross-sectional design of the current study, the temporal relationship of impulsivity and NSSI is unclear. Characteristics associated with impulsive behavior may increase the likelihood of NSSI, or the performance of NSSI may dispose individuals to view and rate themselves as having these characteristics. Longitudinal research is needed to clarify the role of UPPS traits in the etiology and maintenance of NSSI. 


\section{References}

Alderson, R. M., Rapport, M. D., \& Kofler, M. J. (2007). Attention-deficit/hyperactivity disorder and behavioral inhibition: A meta-analytic review of the stop-signal paradigm. Journal of Abnormal Child Psychology, 35, 745-758.

Andover, M. S., Pepper, C. M., Ryabchenko, K. A., Orrico, E. G., \& Gibb, B. E. (2005). Selfmutilation and symptoms of depression, anxiety, and borderline personality disorder. Suicide and Life-Threatening Behavior, 35, 581-591.

Barratt, E. S. (1985). Impulsiveness subtraits: Arousal and information processing. In J. T. Spence \& C. E. Izard (Eds.), Motivation, emotion, and personality (pp. 137-146). Amsterdam: Elsevier Science Publishers.

d'Acremont, M., \& van der Linden, M. (2007). How is impulsivity related to depression in adolescence? Journal of Adolescence, 30, 271-282.

Enticott, P. G., Ogloff, J. R. P., \& Bradshaw, J. L. (2006). Associations between laboratory measures of executive inhibitory control and self-reported impulsivity. Personality and Individual Differences, 41, 285-294.

Evans, C., \& Lacey, J. H. (1992). Multiple selfdamaging behaviors among alcoholic women. A prevalence study. British Journal of Psychiatry, 161, 643-647.

Evans, J., Platts, H., \& Liebenau, A. (1996). Impulsiveness and deliberate self-harm: A comparison of "first-timers" and "repeaters." Acta Psychiatrica Scandinavica, 93, 378-380.

Eysenck, H. J., \& Eysenck, S. B. G. (1991). Manual of the Eysenck Personality Scales. London: Hodder and Stoughton.

Favazza, A. R., \& Conterio, K. (1989). Female habitual self-mutilators. Acta Psychiatrica Scandinavica, 79, 282-289.

Fischer, S., Smith, G. T., \& Anderson, K. G. (2003). Clarifying the role of impulsivity in bulimia nervosa. International Journal of Eating Disorders, 33, 406-411.

Gerbing, D. W., Ahadi, S. A., \& Patton, J. H. (1987). Toward a conceptualization of impulsivity: Components across the behavioral and self-report domains. Multivariate Behavioral Research, 22, 357-379.

Gratz, K. L. (2001). Measurement of deliberate selfharm: Preliminary data on the Deliberate SelfHarm Inventory. Journal of Psychopathology and Behavioral Assessment, 23, 253-263.

Gratz, K. L., \& Roemer, L. (2008). The relationship between emotion dysregulation and deliberate selfharm among female undergraduate students at an urban commuter university. Cognitive and Behaviour Therapy, 37, 14-25.
Hawton, K., Rodham, K., Evans, E., \& Weatherall, R. (2002). Deliberate self harm in adolescents: Self report survey in schools in England. British Medical Journal, 325, 1207-1211.

Heath, N. L., Toste, J. R., Nedecheva, T., \& Charlebois, A. (2008). An examination of nonsuicidal self-injury among college students. Journal of Mental Health Counseling, 30, 137-156.

Herpertz, S., Sass, H., \& Favazza, A. (1997). Impulsivity in self-mutilative behavior: Psychometric properties and biological findings. Journal of Psychiatric Research, 31, 451-465.

Hilt, L. M., Nock, M. K., Lloyd-Richardson, E. E., \& Prinstein, M. J. (2008). Longitudinal study of nonsuicidal self-injury among young adolescents: Rates, correlates, and preliminary test of an interpersonal model. Journal of Early Adolescence, 28, 455-469.

Janis, I. B., \& Nock, M. K. (2009). Are self-injurers impulsive? Results from two behavioral laboratory studies. Psychiatry Research, 169, 261-267.

Klonsky, E. D. (2007). The functions of deliberate self-injury: A review of the evidence. Clinical Psychology Review, 27, 226-239.

Klonsky, E. D., \& Glenn, C. R. (2009). Assessing the functions of non-suicidal self-injury: Psychometric properties of the Inventory of Statements About Self-injury (ISAS). Journal of Psychopathology and Behavioral Assessment, 31, 215-219.

Klonsky, E. D., \& Olino, T. M. (2008). Identifying clinically distinct subgroups of self-injurers among young adults: A latent class analysis. Journal of Consulting and Clinical Psychology, 76, 22-27.

Klonsky, E. D., Oltmanns, T. F., \& Turkheimer, E. (2003). Deliberate self-harm in a nonclinical population: Prevalence and psychological correlates. American Journal of Psychiatry, 160, 1501-1508.

Lacey, J. H., \& Evans, C. D. H. (1986). The impulsivist: A multi-impulsive personality disorder. British Journal of Addiction, 81, 641-649.

Laye-Gindhu, A., \& Schonert-Reichl, K. A. (2005). Nonsuicidal self-harm among community adolescents: Understanding the "whats" and "whys" of self-harm. Journal of Youth and Adolescence, 34, 447-457.

Linehan, M. M. (1993). Skills training manual for treating borderline personality disorder. New York: Guilford Press.

Logan, G. (1994). On the ability to inhibit thought and action. In D. Dagenbach \& T. H. Carr (Eds.), Inhibitory processes in attention, memory and language (pp. 189-239). San Diego: Academic Press.

Logan, G. D., \& Cowan, W. B. (1984). On the ability to inhibit thought and action: A theory of an act of control. Psychological Review, 91, 295-327.

Logan, G. D., Schachar, R. J., \& Tannock, R. (1997). Impulsivity and inhibitory control. Psychological Science, 8, 60-64. 
McCrae, R. R., \& Costa, P. T., Jr. (1990). Personality in adulthood. New York: Guilford Press.

Miller, J., Flory, K., Lynam, D. R., \& Leukefield, C. (2003). A test of the four-factor model of impulsivity-related traits. Personality and Individual Differences, 34, 1403-1418.

Moeller, F. G., Barratt, E. S., Dougherty, D. M., Schmitz, J. M., \& Swann, A. C. (2001). Psychiatric aspects of impulsivity. American Journal of Psychiatry, 158, 1783-1793.

Nock, M. K., \& Prinstein, M. J. (2004). A functional approach to the assessment of self-mutilative behavior. Journal of Consulting and Clinical Psychology, 72, 885-890.

Nock, M. K., \& Prinstein, M. J. (2005). Contextual features and behavioral functions of self-mutilation among adolescents. Journal of Abnormal Psychology, 114, 140-146.

Pattison, E. M., \& Kahan, J. (1983). The deliberate self-harm syndrome. American Journal of Psychiatry, 140, 867-872.

Plutchik, R., van Praag, H. M., Picard, S., Conte, H. R., \& Korn, M. (1989). Is there a relation between the seriousness of suicidal intent and the lethality of the suicide attempt? Psychiatry Research, 27, 71-79.

Ross, S., \& Heath, N. (2002). A study of the frequency of self-mutilation in a community sample of adolescents. Journal of Youth and Adolescence, 31, 67-77.

Simeon, D., Stanley, B., Frances, A., Mann, J. J., Winchel, R., \& Stanley, M. (1992). Self-mutilation in personality disorders: Psychological and biological correlates. American Journal of Psychiatry, 149, 221-226.
Smith, G. T., Fischer, S., Cyders, M. A., Annus, A. M., Spillane, N. S., \& McCarthy, D. M. (2007). On the validity and utility of discriminating among impulsivity-like traits. Assessment, 14, 155-170.

Spitzer, R. L., Kroenke, K., \& Williams, J. B. W. (1999). Validation and utility of a self-report version of Prime-MD: A PHQ primary care study. Journal of the American Medical Association, 282, 1787-1788.

Whiteside, S. P., \& Lynam, D. R. (2001). The five factor model and impulsivity: Using a structural model of personality to understand impulsivity. Personality and Individual Differences, 30, 669-689.

Whiteside, S. P., \& Lynam, D. R. (2003). Understanding the role of impulsivity and externalizing psychopathology in alcohol abuse: Application of the UPPS impulsive behavior scale. Experimental and Clinical Psychopharmacology, 11, 210-217.

Whiteside, S. P., Lynam, D. R., Miller, J. D., \& Reynolds, S. K. (2005). Validation of the UPPS Impulsive Behavior Scale: A four-factor model of impulsivity. European Journal of Personality, 19, 559-574.

Whitlock, J., Eckenrode, J., \& Silverman, D. (2006). Self-injurious behaviors in a college population. Pediatrics, 117, 1939-1948.

Zlotnick, C., Shea, M. T., Pearlstein, T., Simpson, E., Costello, E., \& Begin, A. (1996). The relationship between dissociative symptoms, alexithymia, impulsivity, sexual abuse, and self-mutilation. Comprehensive Psychiatry, 37, 12-16.

Zuckerman, M. (1994). Behavioral expressions and biosocial bases of sensation seeking. New York: Cambridge University Press. 